\title{
Could Face Presence In Print Ads Influence Memorization?
}

\author{
Olivier Droulers, Ph.D, MD, Graduate School of Management (IGR), France
}

Safaa Adil, Graduate School of Management (IGR), France

\begin{abstract}
A large amount of literature in psychology and neurosciences demonstrates that attention is preferentially and automatically oriented toward faces. This stimulus is fixed longer and processed faster compared to other classes of visual stimuli (objects). This article investigates if and how face presence in print ads affects the memorization of ads content. A folder test procedure was used where ads, with or without faces, were inserted. Findings suggest that face presence in ads image positively influences ads memorization. Implications for advertising conception and promotion campaigns are discussed.
\end{abstract}

Keywords: Folder Test; Face; Memorization; Ads

\section{INTRODUCTION}

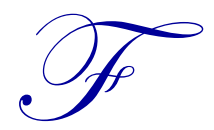

or a primary goal of survival, a human has to process, at every moment, all stimuli present in his visual field. However, given both his limited cognitive resources and the complexity of his visual environment, the human developed an automatic hierarchisation of all these different stimuli to process them according to their importance. In this work we shed a light on (human) face specificity as a stimuli category that receive an advantaged attentional processing based on a specific and dedicated brain network. In advertising we can observe that some print ads focus on the product while others present a human figure (often limited to the facial part). Little or no research has examined if allocating attention toward ads is affected by face presence in advertising. In this study, using a folder test we examine the influence of face presence in print ads on product and brand memorization.

\section{THEORETICAL FRAMEWORK AND RESEARCH HYPOTHESIS}

Faces are a special class of stimuli due to the wealth of information they convey. They give information on both physical features of the observed person (age, sex, ethnicity, identity) and his emotional state. Recently, neurosciences have demonstrated that evolution has established specific neural networks dedicated to face processing probably because it concentrates a large number of relevant perceptual cues for both individual survival and the establishment of social relations. The identification of this brain network allows a better understanding of the effortless attentional processing of faces compared to many other categories of stimuli.

\section{The Neural Basis of Face Processing}

According to Coltheart (1999), the human brain has evolved to dedicate some specific neural networks for processing some categories of information considered essential for the survival and the development of our species.

Faces neural circuits. Neuroscience studies using functional magnetic resonance imaging (fMRI) have shown that participants exposed to images of faces (vs. images of objects) have greater activation in the right occipito-temporal brain area, called Fusiform Face Area (FFA) (Kanwisher, McDermott and Chun, 1997) and in the inferior occipital gyrus, known as the Occipital Face Area (OFA) (Gauthier et al. 2000, Sato et al. 2014). Afterwards, other brain areas preferentially involved in face processing were progressively identified (Lai et al., 2014; Musch et al., 2014). In their model of the distributed human neural system for face perception, Haxby, 
Hoffman and Gobbini (2000) suggested that face processing involves the inferior occipital gyrus responsible of the analysis of facial features, the superior temporal sulcus responsible for changing aspects of faces (e.g. facial expression) and FFA responsible for invariant aspects of faces.

Expertise hypothesis. Several researchers have faced the idea that FFA is a brain area which is only activated by faces and have developed a competing theory. For these authors (Diamond and Carey, 1986), FFA is activated when stimuli processing requires a high degree of expertise (expertise hypothesis). Supporting this theory, it has been observed that the presentation of birds to ornithologists provoked FFA activation as in the presentation of cars to auto experts. If the presentation of birds images activates the FFA only among ornithologists, the presentation of faces activates the FFA for all individuals, maybe because we all have developed a high degree of expertise for faces. Indeed, we are all able to recognize a human face in fewer than 200 milliseconds even though faces are very similar (homogeneous group) compared to other categories.

The debate around the issue of face specific neural processing is still not resolved. However it seems that face is a very particular stimulus: no other class of stimuli has a high number of neurons dedicated to its processing. For many authors this is the reason behind eased face attentional processing.

\section{The Attentional Processing of Faces}

Many psychological studies using different protocols converge to show that the face is a particular stimulus retaining a privileged allocation of attention.

Preference for face processing: The preference for human stimuli occurs from birth. Many studies found that ever since the early months, infants showed a preference for the human stimuli at which they gazed more than objects (Zieber et al., 2013). Moreover, this tendency increases with age (Franck et al. 2014). For Weaver and Lauwereyns (2011) "faces receive mandatory processing when competing for attention with stimuli of less sociobiological salience".

Attentional blink. This phenomenon is highlighted by asking participants to detect targets among distractors presented quickly. In 1992, Raymond, Shapiro, and Arnell showed that the identification of the first target (T1) makes it impossible to identify the second one (T2) when both targets are very close (between 100 and 500 milliseconds). This phenomenon of "attentional blink " is now established for many stimuli (words, numbers, colors) but Awh et al. (2004) showed that it was absent for faces : even presented shortly after the target (T1), and unlike other stimuli, faces are detected by the participants.

Change blindness. When a major change occurs rapidly in a scene (e.g. the removal of a house in a landscape) a participant may take several seconds to notice it. This phenomenon has been demonstrated for example when the change occurred during an eye blink or when a blank screen was inserted between the original image and the modified image. However Ro, Russell and Lavie (2001) showed that when the change involved a face, change blindness lasted much shorter than when the change involved clothing, musical instruments, food or plants.

Dual task paradigm. When we try to perform many tasks simultaneously, performances tend to decline. However, if a task does not require attentional resources (automatic processing), it will not interfere in achieving another task. Researchers have found that the basic visual properties (color, orientation and direction of movement) could be discriminated without attention, but that attentional resources are needed to deal with more complex stimuli. Reddy, Wilken and Koch (2004) asked participants to perform a task A (decide whether a face presented in the periphery was male or female) alone or with a task B (whether 5 letters presented in the middle of the screen, in different spatial orientation were identical, a task known to engage high attentional resources). Even when the face is a complex stimulus, the performance was the same in both situations (task A performed alone or in conjunction with task B), according to the authors, this showed that detection of face gender can be performed without focusing attention. 


\section{Relationship between Visual Attention and Memory}

The link between attention toward a stimulus and its memorization has been widely studied and was a subject of a large consensus in psychology: greater allocation of attention to a stimulus facilitates its memorization. For example, Uncapher and Wagner (2009) suggested that the formation of memories of an event is affected by attention during its encoding, ("allocating goal-directed attention during event processing increases the probability that the event will be remembered later"). Lozitoa and Mulligan (2010) and Gaspelin, Ruthruff and Pashler (2013) showed that attention at encoding had a positive effect on memorial performance. In marketing, many studies have investigated the link between attention to a stimulus and its memorization. Lynch and Srull (1982) explained that information that capture one's attention is processed more extensively, and subsequently is much more likely to be recalled than information that do not capture attention

Thus, based on research in psychology and neurosciences which demonstrated that on the one hand, face presence in a visual field increases catching attention more than other visual stimuli, on the other hand paying attention to a stimulus increases its memorization, we state:

H1: Human face present in a print ad is better recalled than object.

If human presence in ads is better memorized than object, one question remains to be answered if attention to human face would influence ads content memorization. To the best of our knowledge, no work has been done on the influence of human face on print ads memorization, especially reproducing natural exposure conditions (the folder test procedure is used to avoid forced exposure effects). Rosbergen et al. (1997) showed that increased attention to advertising improves the brand recall. Pieters and Wedel (2004) revealed the existence of a transfer of attention from the image of a print ad to the brand "elements "attention to a particular ad element may also spill over to other ad elements" The idea of attention transfer has been suggested since the beginning of print advertisement. Thus, a higher attention to an ads' element will be beneficial to the brand (transfer of attention) for its best memorization. We propose to test:

H2: Face presence in a print advertisement has a positive influence on the recall $(\mathrm{H} 2 \mathrm{a})$ and the recognition $(\mathrm{H} 2 \mathrm{~b})$ of the product category.

H3: Face presence in a print advertisement has a positive influence on the recall (H3a) and the recognition (H3b) of the brand.

\section{RESEARCH METHODOLOGY}

\section{Participants and Experimental Equipment}

One hundred sixteen young adults (58 women), aged between 17 and 30 years $(\mathrm{M}=20.66, \mathrm{SD}=2.75)$, students or people starting a professional activity participated in the experiment.

We created a fictive travel magazine of 14 pages (folder test) in which we inserted 4 ads, with or without a face. The ads concerned products that may be purchased and/or consumed by both men and women. To avoid effects due to a prior exposure to the brand (uncontrolled source of variance), we chose unknown brands, foreign and not marketed in the country of the test: Krocker (candy bar), Hawai (soda), Crystal (ice cream), Baïko (yogurt). Two distractive ads for well-known brands were also inserted (ClubMed and Lay's) to ensure that participants will not question the presence of unknown brands only.

For each brand, two versions of the ad were created using Adobe Photoshop CS5. In one version, a face was inserted (young Caucasian female face; unknown to avoid celebrity effect). In the second one, we inserted in the same position an object. Other advertising elements remain identical, we made advertisements of the same size (7.3 inch * $5.4 \mathrm{inch}$ ) and we inserted them in the same position (bottom of the right-hand pages) in pages 3, 5, 11 and 13. The distractor ads were inserted in page 7 and 9 . We gave each participant a folder test in which were inserted two 
advertisements containing a face, and two advertisements without face (but with an object). The order of the ads was randomized.

\section{Procedure}

Participants were asked to evaluate a new magazine. They looked through the magazine for 4 minutes without interruption. Then, a "surprise" memory task was proposed including a free recall test (participants should restitute all the elements of the advertisements they remembered), a cued recall of product categories and brands presented in ads, then a recognition task for product categories and brands was carried out (with a list of 16 items, 1 target for 3 distractors). Finally, the participants answered questions about their purchase frequency of the product categories.

\section{RESEARCH FINDINGS}

\section{Face Recall}

The results show that participants retained more elements concerning the face present in advertisement compared to object $\left(\mathrm{M}_{\text {ads with face }}=0.65, \mathrm{M}_{\text {ads }}\right.$ without face $=0.27, \mathrm{t}(115)=4.3, \mathrm{p}=0.00, \mathrm{r}=0.37$ ). Hypothesis 1 is supported.

\section{Product Recall and Recognition}

Face presence has a positive influence on product memorization. The product recall score was higher in the condition with face presence than the condition without face presence $\left(\mathrm{M}_{\text {ads with face }}=0.56, \mathrm{M}_{\text {ads }}\right.$ without face $=0.45$, $\mathrm{t}(115)=4.17, \mathrm{p}=0.032, \mathrm{r}=0.19)$. Also, the recognition score for the product is higher in the condition with face presence than without $\left(\mathrm{M}_{\text {ads with face }}=1.24, \mathrm{M}_{\text {ads without face }}=0.99, \mathrm{t}(115)=4.09, \mathrm{p}=0.000, \mathrm{r}=0.35\right)$. Hypotheses $\mathrm{H} 2 \mathrm{a}$ and $\mathrm{H} 2 \mathrm{~b}$ are supported.

\section{Brand Recall and Recognition}

Face presence has a positive influence on brand memorization. The recall score for brand was higher in the condition with face presence than the condition without face $\left(\mathrm{M}_{\text {ads with face }}=0.32, \mathrm{M}_{\text {ads without face }}=0.18, \mathrm{t}(115)=2.66, \mathrm{p}\right.$ $=0.009, \mathrm{r}=0.24)$. Also, the recognition score for brand is higher in the condition with face presence than without without $\left(\mathrm{M}_{\text {ads } \text { with face }}=0.73, \mathrm{M}_{\text {ads without face }}=0.50, \mathrm{t}(115)=3.24, \mathrm{p}=0.002, \mathrm{r}=0.29\right)$. Hypotheses H3a and H3b are supported.

Table 1. Face recall, product and brand recall and recognition scores

\begin{tabular}{lccc}
\hline & Ads with face & Ads without face & P (two-tailed) \\
\hline Face vs object recall & 0.65 & 0.27 & 0.000 \\
\hline Product recall & 0.56 & 0.45 & 0.032 \\
\hline Brand recall & 0.32 & 0.18 & 0.009 \\
\hline Product recognition & 1.24 & 0.99 & 0.000 \\
\hline Brand recognition & 0.73 & 0.50 & 0.002 \\
\hline
\end{tabular}

\section{DISCUSSION}

The face is a unique visual stimulus. A large amount of literature in neurosciences and psychology have demonstrated that the face benefits from a priority in allocation of attention compared to other categories of inanimate (objects) or animated (animals) stimuli. It receives an automatic processing which is fast, non-conscious, and requires a minimum of attentional resources (Langton, Law, Burton,and Schweinberger, 2008). Our results corroborate these findings.

By inserting a face in a print advertisement, we found a better memorization of adverting content. This result is particularly interesting because it has not been obtained under forced exposure conditions but using a folder 
test. Thus participants' attention has not been directed towards any advertising by the experimenter or by the used experimental procedure. In other words, in a fully charged environment (a magazine with a lot of information), face present in advertising particularly caught attention.

There are differing academic opinions about the influence of pictures on ads effectiveness. For Edell and Staelin (1983) "the presence of a dominant picture in a print ad can alter a consumer's cognitive activity while viewing the ad". On the other hand, Pieters and Wedel (2004) suggest a positive effect of the presence of an image in advertising since, according to these authors, there is a positive transfer of attention from the image to other print ads elements. In the specific case of the face, our results support Pieters and Wedel's findings. We found that greater attention to the face in print ads was not deleterious for the memorization of other elements present in ads. Rather the opposite; attention to the face seems to be beneficial for product and brand. The product category and brand recall as well as recognition were significantly improved with face presence in advertising.

\section{CONCLUSION}

The contribution of this work is to show that all visual elements present in ads are not equal in terms of catching consumers' attention. The face is a very important source of information in human social life. This type of visual stimulus has privileged processing in comparison to other objects. The face has a demonstrable effect on attention to print advertisements as a whole. If advertisers fail to catch consumers' attention, the effective reach of a print advertisement is reduced. Advertisers are continually searching for conditions that increase attention values for their messages. Our findings suggest that inserting a face in print ads increases attention to ads and therefore increases their memorization. The visual of a human face can be used in advertising campaigns which aim at enhancing the knowledge or the memorization of the product and the brand.

Limitations of this study offer opportunities for further research. First, our experiment was conducted using products of general consumption; it would be interesting to replicate it with other types of products. We only used female faces, we can imagine a future study of the influence of gender and congruence model/reader. According to Brasel (2011), a consumer's visual attention depends on the nature of the media he is exposed to. We tested the influence of face presence in print ads (passive media). Future research could reproduce the experiment using an interactive media. Then, in this study advertising effectiveness was measured in terms of memorization; future studies can examine other variables, such as the effect of face presence in ads on ads evaluation and consumer attitude.

\section{AUTHOR INFORMATON}

Olivier Droulers is a Full Professor of Marketing at the Institut de Gestion de Rennes (Graduate School of Management, Rennes 1 University, France). Earlier in this university he received a MD and a PhD. His research interests are about the consequences of the importation of the neuroscience paradigm in management sciences and particularly in marketing. E-mail olivier.droulers@univ-rennes1.fr

Safaa Adil is a PhD Student and Research and teaching fellow (ATER) in marketing at the Institut de Gestion de Rennes (Graduate School of Management, Rennes 1 University, France). She is preparing a PhD. E-mail: safaa.adil@etudiant.univ-rennes1.fr

\section{REFERENCES}

Awh E., Serences, J., Laurey, P., Dhaliwal, H., Van der Jagt, T., and Dassonville, P. (2004). Unimpaired Face Discrimination During the Attentional Blink: Evidence for Multiple Processing Channels. Cognitive Psychology, 48 (1), 95-26.

Brasel, S.A. (2011). Nonconscious drivers of visual attention in interactive media environments. Journal of brand management, 18 (7), 473-482.

Coltheart, M. (1999). Modularity and cognition. Trends in cognitive sciences, 3 (3),115-120.

Diamond, R., and Carey, S. 1986. Why faces are and are not special: An effect of expertise. Journal of Experimental Psychology: General, 115 (2), 107-117. 
Edell, J.A., and Staelin,R. (1983). The Information Processing of Pictures in Print Advertisements. Journal of Consumer Research, 10 (1), 45-61.

Frank, M.C., Amso, D., and Johnson, S.P. (2014). Visual search and attention to faces during early infancy, Journal of Experimental Child Psychology, 118, 13-26.

Gaspelin, N., Ruthruff, E., and Pashler, H. (2013). Divided attention: An undesirable difficulty in memory retention. Memory andCognition, 41 (7), 978-988.

Gauthier, I., Tarr, M.J., Moylan, J., Skudlarski, P., Gore, J.C., and Anderson, A.W. (2000). The fusiform 'face area' is part of a network that processes faces at the individual level. Journal of Cognitive Neuroscience, 12 (5), $495-504$.

Haxby, J.V., Hoffman, A.E., and Gobbini, M.I. (2000). The distributed human neural system for face perception. Trends in cognitive sciences, 4 (6), 223-233.

Kanwisher, N., McDermott, J., and Chun, M.M. (1997). The fusiform face area: A module in human extrastriate cortex specialized for face perception. Journal of Neuroscience, 17 (11), $4302-4311$.

Lai, J., Pancaroglu, R., Oruc, I., Barton, J.S., and Davies-Thompson, J. (2014). Neuroanatomic correlates of the feature-salience hierarchy in face processing: An fMRI -adaptation study. Neuropsychologia, 53, 274-283.

Langton, S.R.H., Law, A., Burton, A.M., and Schweinberger, S.R. (2008). Attention capture by faces. Cognition, 107 (1), 330-342.

Lozitoa, J., and Mulligan, N. (2010). Exploring the role of attention during implicit memory retrieval. Journal of Memory and Language, 63 (3), 387-399.

Lynch, J.G. and Srull, T. K. (1982), Memory and Attentional Factors in Consumer Choices Concepts and Research Methods. Journal of Consumer Research, 9, 18-37.

Musch, K., Hamame , C., Perrone-Bertolotti, M., Minotti, L., Kahane, Andreas K. Engel, P.,

Lachaux, J.P., and Schneider, R.T. (2014.) Selective attention modulates high-frequency activity in the faceprocessing network, Cortex, 1-18.

Nixon, H.K. (1924). Attention and Interest in Advertising. Archives of Psychology, 72(1),5-67.

Pieters, R., and Wedel, M. (2004). Attention Capture and Transfer in Advertising: Brand, Pictorial, and Text-Size Effects. Journal of Marketing, 68 (2), 36-50.

Poffenberger, A.T. (1925). Psychology in Advertising. Chicago: A.W. Shaw Company. pp. 156-61.

Raymond, J.E., Shapiro, K.L., and Arnell, K.M. (1992). Temporary suppression of visual processing in an RSVP task: an attentional blink? Journal of experimental psychology: Human perception and performance, 18 (3),849-60.

Reddy, L., Wilken, P., and Koch, C. (2004). Face Gender Discrimination in the Near-Absence of Attention. Journal of Vision, 4 (2), 106-117.

Ro, T. Russell, C., and Lavie, N. (2001). Changing faces: a detection advantage in the flicker paradigm. Psychological Science, 12 (1),94-99.

Rosbergen, E., Pieters, R. and Wedel, M. (1997).Visual Attention to Advertising: A Segment-Level Analysis. Journal of Consumer Research, 24 (3), 305-314.

Sato, W., Kochiyama, T., Uono, S., Matsuda, K., Usui, K., Inoue, U., and Toichi, M. (2014). Rapid, high-frequency, and theta-coupled gamma oscillations in the inferior occipital gyrus during face processing. Cortex, 1-17.

Uncapher, M., and Wagner, A. (2009). Posterior parietal cortex and episodic encoding: Insights from fMRI subsequent memory effects and dual-attention theory. Neurobiology of Learning and Memory, 91 (2), 139154.

Wang, W., Miao, D., and Zhao, L. (2014). Automatic detection of orientation changes of faces versus nonfaceobjects: A visual MMN study. Biological Psychology, 100, 71-78.

Weaver, M.D., and Lauwereyns, J. (2011). Attentional capture and hold: the oculomotor correlates of the change detection advantage for faces. Psychological research, 75, 10-23.

Zieber, N., Kangas, A., Hock, A., Hayden, A., Collins, R., Bada, H., Joseph, J.E., Bhatt, R.S. (2013). Perceptual specialization and configural face processing in infancy, Journal of Experimental Child Psychology, 116, 625-639. 